\section{One Abutment at One Time Concept for Platform-Switched Morse Implants: Systematic Review and Meta-Analysis}

\author{
Joanes Silva Santos ${ }^{1}$, Thiago de Santana Santos², Paulo Ricardo Saquete
}

Martins-Filho ${ }^{2}$, Nadine von Krockow ${ }^{1}$, Paul Weigl ${ }^{3}$, Hess Pablo ${ }^{1}$

\author{
'Department of Oral Surgery \\ and Implantology, School of \\ Dentistry (Carolinum), Johann \\ Wolfgang Goethe - University, \\ Frankfurt am Main, Germany \\ ${ }^{2}$ Investigative Pathology Laboratory, \\ UFSE - Universidade Federal de \\ Sergipe, Aracaju, SE, Brazil \\ ${ }^{3}$ Department of Continuing \\ Education, Dental School (Carolinum), \\ Johann Wolfgang Goethe-University \\ Frankfurt am Main, Germany
}

\section{Correspondence: Hess Pablo, Department of Oral Surgery and Implantology, School of Dentistry (Carolinum), Johann Wolfgang Goethe - University Frankfurt am Main, Frankfurt am Main, Germany. e-mail: p.hess@em.uni-frankfurt.de}

Key Words: dental abutment, platform-switched, marginal bone loss.

\section{Introduction}

Canullo et al. were the first authors to use the term "one abutment - one time" concept to refer to the connection of an immediate non-removal abutment in post-extractive implant (1). This clinical trial showed at 36 months after loading a statistically significant mean difference of 0.2 $\mathrm{mm}$ upper peri-implant marginal bone level in favor of the maintenance of the abutment. Other trials (2-4) also showed a less vertical bone loss after 12 months using definitive abutments, although this may be not clinically perceptible.

Nowadays treatment with implant may incorporate divergent option of treatment that does not follow a general rule. Long-term implants switching platform immediately loaded into smokers had the same results to non-smokers if the abutments were screwed after implant placing and no longer removed (5). Two times dis/reconnections of abutment did not show significant differences in periimplant soft and hard tissues when compared with definitive abutment (6). Researchers have been trying to evaluate whether a definitive abutment has advantage over standard guideline $(1,2,5-7)$.

Albrektsson et al. proposed criteria for the success of a dental implant, including radiographic evidence of crestal bone around the implant, $1.5 \mathrm{~mm}$ bone loss in the first year and $<0.2 \mathrm{~mm}$ bone resorption annually after 1 year of loading (8). Abrahamsson et al. studied the effects of abutment disconnection and reconnection on the periimplant soft-/hard-tissue complex in dogs (9). They observed that abutment handling resulted in marginal bone resorption due to tissue reactions initiated to establish proper biological width, which moved the mucosal barrier apically relative to the soft tissue. Other factors, such as microgaps between the implant and abutment (10), micromovement at the implant-abutment interface (11), microleakage between the implant and abutment (8), and abutment disconnection and/or reconnection (1-3) also affect bone remodeling.

There is a biologic base for the use of non-removal abutment placed after implant insertion. However, this option treatment needs assessment of the potential clinical benefit and risk associated with the technique. The liability of excess cement remainder in the periodontal area and its consequences has been discussed as an adverse outcome, in case with abutment margin depths and immediate cemented restoration (12), which may be prevented with abutment that allow screw-retained crowns (6). Another disadvantage associated with definitive abutment after surgery is the difficulty of selecting the appropriate definitive standard abutment immediately after implant insertion, concerned to high soft tissue and wall bone variance (12) that can be prevented by using customized abutments (13).

\section{Material and Methods Aim}

The aim of this systematic review and meta-analysis was to compare the peri-implant vertical bone loss of 
immediate loading of implant crowns using the one abutment at one time (AOT) protocol and implants with abutment removal (AR).

\section{Methods}

This systematic review with meta-analysis was reported according to the PRISMA (Preferred Reporting Items for Systematic Reviews and Meta-Analyses) statement $(14,15)$, with guidance from the Cochrane Collaboration Handbook (16). A protocol was designed a priori and registered in the PROSPERO database (registration number CRD42015029682).

\section{Search Strategy}

A comprehensive search in PubMed database was performed to identify studies published in English that compared peri-implant marginal bone loss with the use of immediate, platform-switched restorations with definitive abutments and those with provisional abutments. The search was performed in September 2016 using the following strategy: ((implant-abutment OR dental implantabutment) and (one abutment-one time OR one abutment time concept $O R$ immediate loading)) and (bone loss OR bone level $\mathrm{OR}$ bone preservation). Reference lists of original articles and reviews were searched to identify additional studies that could not be located in the electronic database.

\section{Eligibility Criteria and Outcome}

Two reviewers (JSS and TSS) independently screened the search results and identified potentially relevant studies based on titles and abstracts. Potentially relevant studies were read in full, and those fulfilling the eligibility criteria were included in the meta-analysis. Disagreements between reviewers (JSS and TSS) were resolved by consensus or by a third reviewer (PRSM-F).

The following elements to define the eligibility criteria were used: (1) population: patients undergoing implantbased prosthetic rehabilitation, (2) comparison groups: implant placement using an AOT protocol versus AR protocol, (3) predefined outcome: peri-implant vertical bone loss, and (4) study type: randomized clinical trials (RCTs). Studies that did not measure bone loss using radiography or computed tomography, and those with mean follow-up time $<3$ months were excluded.

\section{Data Extraction}

Two reviewers (JSS and TSS) extracted data independently using a predefined protocol. Disagreements between reviewers (JSS and TSS) were resolved by consensus or by a third reviewer (PRSM-F). The following data were recorded: study design, sample size, characteristics of study groups, implant characteristics, follow-up period, radiographic evaluation and measurements of peri-implant marginal bone levels.

\section{Assessment of Risk of Bias}

Two reviewers (JSS and TSS) independently assessed trials quality using the Cochrane risk of bias tool (16). Quality was assessed in six domains: selection bias (random sequence generation, allocation concealment), performance bias (blinding of participants and personnel), detection bias (blinding of outcome assessment), attrition bias (completeness of outcome data), reporting bias (selective reporting), and other bias. All domains were judged as having low, high or unclear risk of bias.

\section{Statistical Analysis}

The primary endpoint was the change in peri-implant vertical bone level in millimeters from baseline. It were pooled data with a random-effect meta-analysis with weighted mean differences (WMDs) and 95\% Cls reported. Heterogeneity was investigated by the Cochran 0 test using a cut-off of $10 \%$ for significance and quantified using the I2 index [100\% x (0-df)/0]. It was used subgroup analysis to assess whether the different follow-up times led to different results. A random-effects meta-regression analysis was used to assess the significance of the differences. R2 index was used to quantify the proportion of variance explained by the follow-up time. Two-sided p-values lower than 0.05 were considered statistically significant. The data were analyzed using the statistical software Review Manager 5.3 (Cochrane IMS, Copenhagen, Denmark). Meta-regression was performed by using RStudio (version 0.98.1083).

\section{Results}

The search strategy resulted in the identification of 103 records from the PubMed database and reference lists of included articles. After the screening of titles and abstracts, the eligibility of eight full-text articles was assessed. Five studies $(1,3,4,6,7)$ (four multicentre RCTs, and one prospective RCT) published between 2010 and 2015 were included in this review (Fig. 1).

\section{Risk of Bias}

In the five studies included in this review, participants were randomly assigned using a random number generator to one of two treatment groups. However, it was observed a high risk of selection bias in most studies $(1,3,4,7)$, since the allocation was not concealed. In the study by Luongo et al. (7), protocol deviations including breaking of the random codes were described. A low risk of detection $(1,4,6,7)$ and attrition $(1,3,4,7)$ bias was observed in four of the five $(80 \%)$ studies. The risk of performance and 
reporting bias was judged as unclear for all studies. In addition, there was insufficient information to permit judgment on other biases (Fig. 2).

\section{General Characteristics and Health Status of Included Patients}

The five studies included 174 patients (intervention [AOT protocol], $n=89$; control [standard protocol], $n=85$ ). The mean patient age was 55.2 years, and the sex distribution was similar in the two groups.

Patients' health status was characterized as "good" in

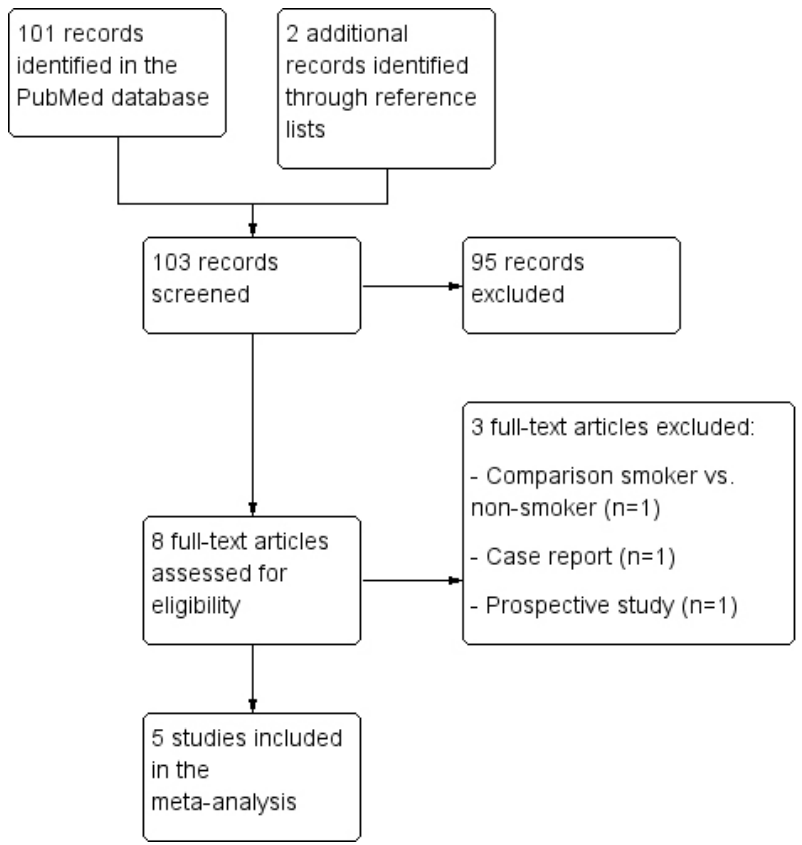

Figure 1. Flow diagram showing study selection for meta-analysis. two studies $(3,4)$, although one patient had well-controlled diabetes. In the three remaining studies $(1,6,7)$, general health status was defined by inclusion and/or exclusion criteria. In one study (1), periodontal health status was controlled by excluding patients with full-mouth plaque and bleeding scores $>25 \%$. Two studies $(3,4)$ excluded patients with plaque indices $\leq 2$, based on periodontal screening and recording performed during the first visit. In the remaining two studies $(6,7)$, information regarding periodontal health status was unclear. Patients who smoked $>10(1,3,6)$ or $>20(4)$ cigarettes per day were excluded from four studies. In one study (7), the authors included non-smokers and smokers.

\section{Implant Characteristics}

A total of 258 implants were placed using definitive $(n=123)$ and provisional $(n=135)$ abutments. Four implant systems (Ankylos ${ }^{\circledR}$ [Dentsply Implants, Mannheim, Germany], JDEvolution ${ }^{\circledR}$ [JDentalCare, Modena, Italy], Global ${ }^{\circledR}$ [Sweden and Martina, Padua, Italy], and Straumann ${ }^{\circledR}$ Bone Level [Straumann, Basel, Switzerland]) were used in the five studies. Implant lengths ranged from 8 to $15 \mathrm{~mm}$ and diameters ranged from 3.5 to $5.5 \mathrm{~mm}$.

Four of the five $(80 \%)$ studies used similar surgical protocols for dental implant placement. Implants were placed with the implant-abutment interface at the bone crest level in these studies $(1,3,4,6)$, whereas Luongo et al. placed implants at least $1 \mathrm{~mm}$ beneath this level to the palatal wall (7). In one study (4), implants were placed immediately into extraction sites. In the study by Luongo et al. (7) (12\%) post-extractive implants were included in the definitive abutment group and one (1\%) in the removal abutment group (7). Custom abutments for single-tooth

Random sequence generation (selection bias)

Allocation concealment (selection bias)

Blinding of participants and personnel (performance bias)

Blinding of outcome assessment (detection bias)

Incomplete outcome data (attrition bias)

Selective reporting (reporting bias)

Other bias

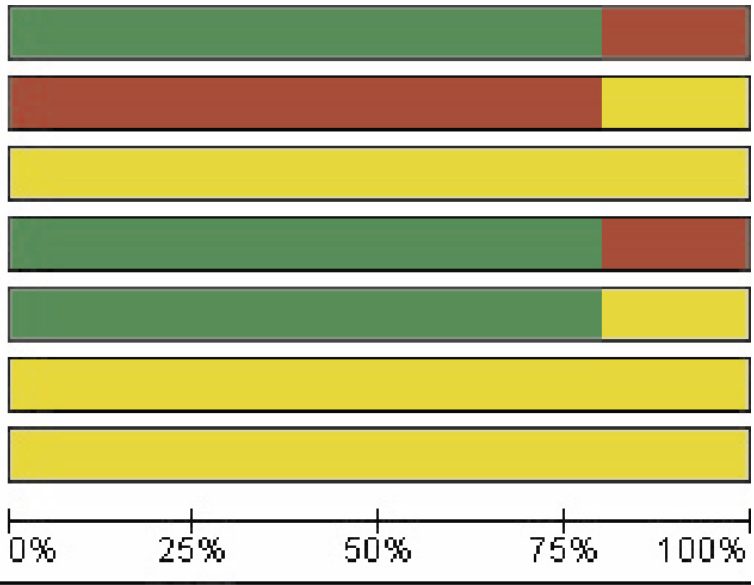


implants were used in two studies $(3,4)$, whereas abutments provided by the respective manufacturers were used in the remaining studies $(1,6,7)$. Four studies $(3,4,6,7)$ provided information on provisional abutment disconnection and reconnection, but protocols were not uniform. Grandi et al. $(3,4)$, Canullo et al. (1), and Koutouzis et al. (6) used cement-retained implant crowns; whereas the implantretained method used by Luongo et al. (7) was unclear. Table 1 summarizes the major characteristics of the studies.

Radiographic Evaluation and Measurement of PeriImplant Vertical Bone Levels

In all studies, the peri-implant marginal bone level was measured using periapical radiographs and digital imaging software, taking into account the distal and mesial surfaces of each implant. Linear measurements were made using the most coronal portion of the implant shoulder margin and the most coronal point of bone-implant contact. An increase in the vertical distance between landmarks on consecutive radiographs was considered to be indicative of peri-implant marginal bone loss. All studies used radiographs as the baseline for the following radiographic evaluations. The minimum and maximum follow-up periods were 3 and 36 months following implant placement.

At the 3-month follow up, two studies $(1,6)$ reported no difference in mean peri-implant bone loss between treatments performed with the $\mathrm{AOT}$ and standard protocols. Within 3 to 6 months after loading, results varied among studies $(3,4,6)$. At 12 months, differences in peri-implant bone levels were observed between groups in two studies (2-4). Compared with provisional implants, definitive abutments resulted in less bone loss. Canullo et al. (1) reported similar results during long-term follow up (18 and 36 months; Table 2).

\section{Meta-Analysis}

The five studies were included in the meta-analysis for the evaluation of peri-implant vertical bone loss. There was less peri-implant vertical bone loss at implants using an AOT protocol than at implants using AR protocol (Weighted mean difference [WMD] $-0.19,95 \% \mathrm{Cl}-0.26$ to -0.13 ; $\mathrm{p}<0.0001$; random-effects model). The subgroup analysis showed no differences in the bone loss at the first 6 months of follow-up. However, WMD of peri-implant vertical bone loss between AOT and AR protocols was found statistically significant at 6 months $<\mathrm{t} \leq 12$ months (WMD $-0.40,95 \% \mathrm{Cl}$ -0.53 to $-0.27 ; p<0.0001$; random effects model) and 1 year $<\mathrm{t} \leq 3$ years (WMD $-0.16,95 \% \mathrm{Cl}-0.27$ to $-0.05 ; \mathrm{p}=0.004$; random effects model). The test of heterogeneity among all studies showed heterogeneity $(p<0.0001,12=96 \%)$, as well as the test for subgroup differences (inconsistency across the subgroups) ( $p<0.0001,12=87.4 \%$ ) (Fig. 3). 


\section{Meta-Regression}

The meta-regression analysis showed an increase of the WMD in the bone loss with the increase in the follow-up time, although not statistically significant $(p=0.132 ; y=-$ 0.0670-0.0145x). According to the prediction equation, it is expected an increase of approximately $0.2 \mathrm{~mm}$ in WMD for each year in follow-up time. Heterogeneity was not explained by meta-regression for follow-up time

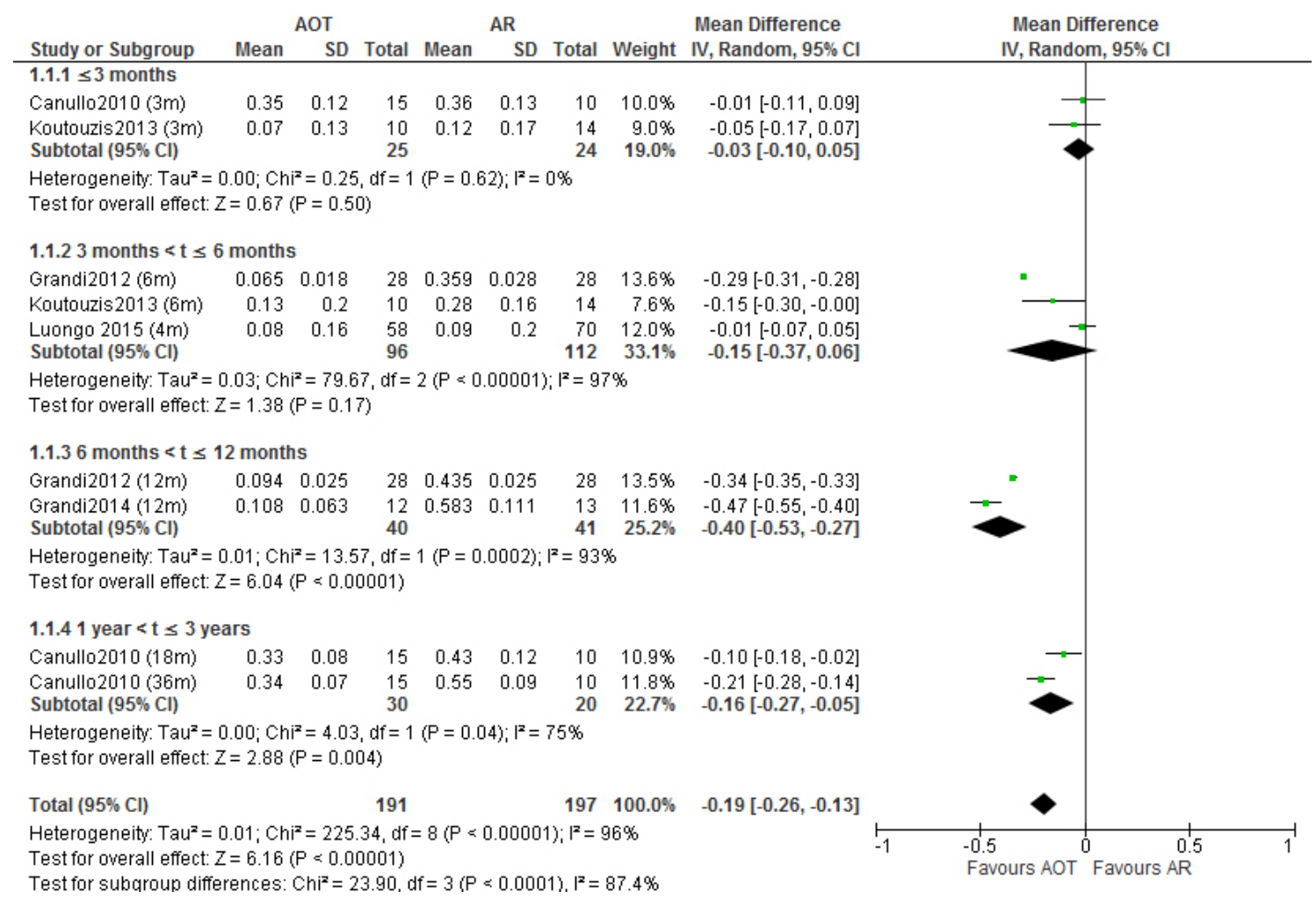

Figure 3. Forest plot of mean difference of effects of AOT and AR protocols on peri-implant vertical bone loss.

Table 2. Peri-implant vertical bone loss according to follow-up time across studies

\begin{tabular}{|c|c|c|c|c|c|}
\hline \multirow{2}{*}{ Studies } & \multirow{2}{*}{$\begin{array}{c}\text { Position of } \\
\text { implant shoulder }\end{array}$} & \multicolumn{2}{|c|}{ Mean peri-implant bone loss (SD) } & \multirow{2}{*}{$\begin{array}{c}\text { Level of } \\
\text { significance }\end{array}$} & \multirow{2}{*}{$\begin{array}{r}\text { Duration o } \\
\text { follow-up }\end{array}$} \\
\hline & & Definitive abutment group & $\begin{array}{l}\text { Provisional } \\
\text { abutment group }\end{array}$ & & \\
\hline \multirow{3}{*}{ Canullo 2010} & \multirow{3}{*}{ Epicrestal } & $0.35 \mathrm{~mm}(0.12)$ & $0.36 \mathrm{~mm}(0.13)$ & n.s. & 3 months \\
\hline & & $0.33 \mathrm{~mm}(0.08)$ & $0.43 \mathrm{~mm}(0.12)$ & $\begin{array}{c}\mathrm{p}=0.051 \\
\text { (borderline) }\end{array}$ & 18 months \\
\hline & & $0.34 \mathrm{~mm}(0.07)$ & $0.55 \mathrm{~mm}(0.09)$ & $\mathrm{p}<0.0001$ & 36 months \\
\hline \multirow{2}{*}{ Grandi 2012} & \multirow{2}{*}{ Epicrestal } & $0.065 \mathrm{~mm}(0.018)$ & $0.359 \mathrm{~mm}(0.028)$ & $\mathrm{p}<0.0001$ & 6 months \\
\hline & & $0.094 \mathrm{~mm}(0.025)$ & $0.435 \mathrm{~mm}(0.025)$ & $\mathrm{p}<0.0001$ & 12 months \\
\hline \multirow{2}{*}{ Koutouzis 2013} & \multirow{2}{*}{ Epicrestal } & $0.07 \mathrm{~mm}(0.13)$ & $0.12 \mathrm{~mm}(0.17)$ & n.s. & 3 months \\
\hline & & $0.13 \mathrm{~mm}(0.20)$ & $0.28 \mathrm{~mm}(0.16)$ & n.s. & 6 month \\
\hline Grandi 2014 & Epicrestal & $0.108 \mathrm{~mm}(0.063)$ & $0.583 \mathrm{~mm}(0.111)$ & $\mathrm{p}<0.0001$ & 12 months \\
\hline Luongo 2015 & Subcrestal & $0.08 \mathrm{~mm}(0.16)$ & $0.09 \mathrm{~mm}(0.20)$ & n.s. & 4 months \\
\hline
\end{tabular}


(adjusted R2=0\%) (Fig. 4).

\section{Discussion}

In this systematic review, the PRISMA recommendations and Cochrane methods were used to evaluate the best evidence for the use of the AOT protocol as an option to limit bone loss after implant placement. Marginal bone loss associated with the immediate loading of platformswitched implant crowns using the AOT protocol was compared with that resulting from the use of the $A R$ protocol. In the included studies, peri-implant bone level was evaluated for 258 implants (123 with definitive and 135 with provisional abutments). Follow-up periods ranged from $3(1,6)$ to $36(1)$ months.

Many factors can affect the peri-implant bone loss level, which is considered to be a criterion for the success of implant therapy (8). Hard- and soft-tissue remodeling may be related to implant preparation, soft tissue-inflammation and biomechanical factors (17). Following the first reports of the effects of abutment disconnection and reconnection on hard and soft tissues $(9,18)$, RCTs confirmed that the AOT concept limits marginal bone loss in comparison with $A R$.

The studies included in this review showed variable degrees of peri-implant bone level change, partially due to the differences in the duration of follow up. Two studies reported no difference in peri-implant bone loss at 3 months $(1,6)$, whereas two studies showed significant differences favoring the use of definitive abutments at 12 months $(3,4)$. The measurement of horizontal and vertical marginal bone changes is considered important because inflammatory cell infiltrate at the implant-abutment junction affect bone remodeling in both directions $(2,19,20)$. This meta-analysis showed that higher follow-up period was associated with less bone loss for one abutment at one time. The first 6 months did not show differences for both treatments. Thus, future studies should be done with longer (>1-year) follow-up.

It was found variation among the included studies in implant system used, clinician, surgical protocol, implant shoulder position, implant placement site, implant diameter, abutment type, and patients' periodontal biotype. Although gingival biotype may affect peri-implant remodeling, and thus the outcome of dental implant procedures $(21,22)$, three studies did not describe patients' periodontal status before implant placement. Patients' tissue biotypes were assessed in two studies $(1,6)$, but the correlation of this parameter with the outcome was not examined in one of these studies (1). Koutouzis et al. found no correlation between bone wall thickness and peri-implant mucosal height 6 months after implant placement involving two ARs, concluding that this treatment yielded results similar to those obtained with the use of definitive abutments (6).

This systematic review with meta-analysis has some limitations and the results should be interpreted with caution. The quality of evidence of the included studies was not optimal; no study had an overall low risk of bias. Standardization of peri-implant marginal bone level measurement was lacking, and only two-dimensional examination was performed in the included studies. Short follow-up periods and the use of different surgical

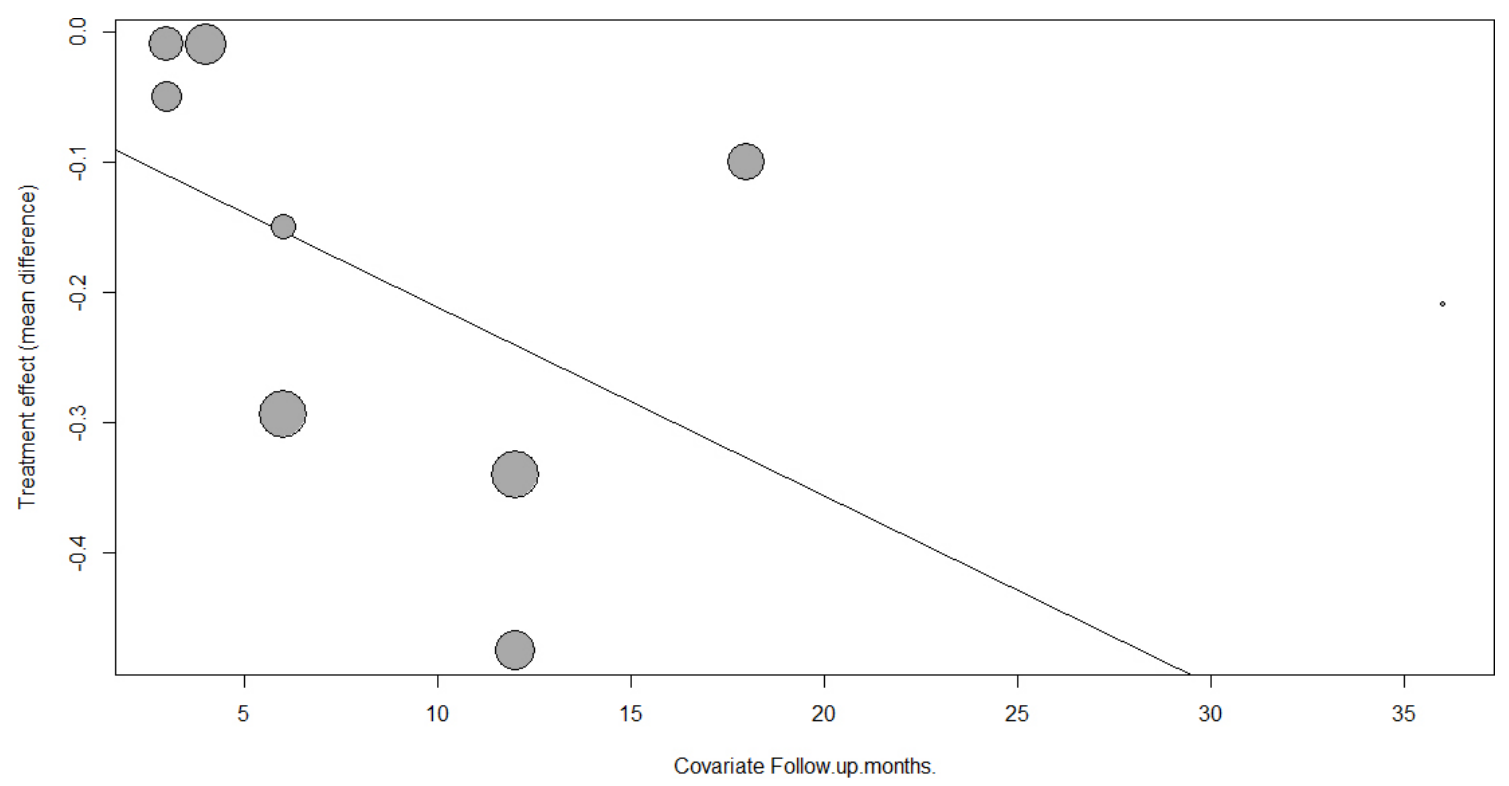

Figure 4. Scatter plot for the meta-regression of the association between the mean difference of the peri-implant vertical bone loss comparing the two protocols and the follow-up time in months. 
protocols likely affected the results. Finally, this review was based on a small sample with considerable heterogeneity. Further randomized clinical studies involving the vertical and horizontal measurement of peri-implant bone levels, evaluation by three-dimensional cone-beam computed tomography, and longer follow-up periods are needed.

In conclusion, this review demonstrated that the use of the AOT protocol with platform-switched Morse implants results in less bone loss than do AR procedures, but this difference may not be clinically relevant. Thus, the preservation of marginal bone level achieved with the AOT protocol may not enhance aesthetics.

\section{Resumo}

0 objetivo desta revisão sistemática e meta-análise foi comparar a perda óssea vertical em implantes de carga imediata usando o protocolo de um pilar em um único momento (AOT) e implantes com remoção de pilar (AR). Esta revisão sistemática com meta-análise foi relatada de acordo com a declaração PRISMA, com orientação do Cochrane Collaboration Handbook. Foram identificadas 103 publicações na base de dados PubMed e nas listas de referência dos artigos examinados. Após a triagem de títulos e resumos, avaliou-se a elegibilidade de oito artigos de texto completo. Cinco estudos publicados entre 2010 e 2015 foram incluídos na metaanálise. Houve menos perda óssea vertical peri-implante em implantes usando o protocolo AOT do que nos implantes usando o protocolo AR (WMD -0,19, 95\% IC -0,26 a -0,13; $p<0,0001$, modelo de efeitos aleatórios). Em conclusão, o uso do protocolo AOT com implantes Cone Morse associados a pilares com plataforma switching resulta em menos perda óssea do que os procedimentos $A R$, mas esse efeito pode não ser clinicamente relevante. A preservação do nível ósseo marginal alcançado com o protocolo AOT pode não melhorar a estética. Estes resultados devem ser interpretados com cautela.

\section{References}

1. Canullo L, Bignozzi I, Cocchetto R, Cristalli MP, Iannello G. Immediate positioning of a definitive abutment versus repeated abutment replacements in post-extractive implants: 3-year follow-up of a randomised multicentre clinical trial. Eur J Oral Implantol 2010;3:285296.

2. Degidi M, Nardi D, Piattelli A. One abutment at one time: non-removal of an immediate abutment and its effect on bone healing around subcrestal tapered implants. Clin Oral Implants Res 2011;22:1303-1307.

3. Grandi T, Guazzi P, Samarani R, Maghaireh H, Grandi G. Immediate positioning of definitive abutments versus repeated abutment replacements in immediately loaded implants: effects on bone healing at the 1-year follow-up of a multicentre randomised controlled trial. Eur J Oral Implantol 2012;5:9-16.

4. Grandi T, Guazzi P, Samarani R, Maghaireh H, Grandi G. One abutmentone time versus a provisional abutment in immediately loaded post-extractive single implants: a 1-year follow-up of a multicentre randomised controlled trial. Eur J Oral Implantol 2014;7:141-149.

5. Romanos G, Grizas E, Laukart E, Nentwig GH. Effects of early moderate loading on implant stability: a retrospective investigation of 634 implants with platform switching and Morse-tapered connections. Clin
Implant Dent Relat Res 2016;18:301-309.

6. Koutouzis $T$, Koutouzis G, Gadalla H, Neiva R.. The effect of healing abutment reconnection and disconnection on soft and hard periimplant tissues: a short-term randomized controlled clinical trial. Int J Oral Maxillofac Implants 2013;28:807-814.

7. Luongo G, Bressan E, Grusovin MG, Neiva R. Do repeated changes of abutments have any influence on the stability of peri-implant tissues? Four-month post-loading preliminary results from a multicentre randomised controlled trial. Eur J Oral Implantol 2015;8:129-140.

8. Albrektsson T, Zarb G, Worthington P, Eriksson AR. The long-term efficacy of currently used dental implants: a review and proposed criteria of success. Int J Oral Maxillofac Implants 1986;1:11-25.

9. Abrahamsson I, Berglundh T, Lindhe J. The mucosal barrier following abutment dis/reconnection. An experimental study in dogs. J Clin Periodontol 1997;24:568-572.

10. Alves CC, Muñoz F, Cantalapiedra A, Ramos I, Neves M, Blanco J. Marginal bone and soft tissue behavior following platform switching abutment connection/disconnection--a dog model study. Clin Oral Implants Res 2015;26:983-991.

11. Piattelli A, Vrespa G, Petrone G, lezzi G, Annibali S, Scarano A. Role of the microgap between implant and abutment: a retrospective histologic evaluation in monkeys. J Periodontol 2003;74:346-352.

12. Linkevicius $T$, Vindasiute $E$, Puisys $A$, Peciuliene V. The influence of margin location on the amount of undetected cement excess after delivery of cement-retained implant restorations. Clin Oral Implants Res 2011;22:1379-1384.

13. Borges T, Lima T, Carvalho A, Dourado C, Carvalho V. The influence of customized abutments and custom metal abutments on the presence of the interproximal papilla at implants inserted in single-unit gaps: a 1-year prospective clinical study. Clin Oral Implants Res 2014;25:12221227.

14. Knobloch K, Yoon U, Vogt PM. Preferred reporting items for systematic reviews and meta-analyses (PRISMA) statement and publication bias. J Cranio-Maxillo-Facial Surg 2011;39:91-92.

15. Moher D, Liberati A, Tetzlaff J, Altman DG; PRISMA Group. Preferred reporting items for systematic reviews and meta-analyses: the PRISMA statement. Int J Surg 2010;8:336-341.

16. Higgins JPT, Altman DG, Gøtzsche $P C$, Jüni $P$, Moher $D$, Oxman $A D$, Savovic J, et al.. The Cochrane Collaboration's tool for assessing risk of bias in randomised trials. BMJ 2011;343:d5928.

17. Zipprich $H$, Weigl $P$, Lange $B$, et al. Micromovements at the implantabutment interface: measurement, causes, and consequences. Implantologie 2007;15:31-46.

18. Lazzara RJ, Porter SS. Platform switching: a new concept in implant dentistry for controlling postrestorative crestal bone levels. Int J Periodontics Restorative Dent 2006;26:9-17.

19. Hermann JS, Buser D, Schenk RK, Schoolfield JD, Cochran DL. Biologic width around one- and two-piece titanium implants. Clin. Oral Implants Res. 2001;12:559-571.

20. Broggini N, McManus LM, Hermann JS, Medina R, Schenk RK, Buser $D$, et al.. Peri-implant inflammation defined by the implant-abutment interface. J. Dent. Res. 2006;85:473-478.

21. Esfahrood ZR, Kadkhodazadeh M, Talebi Ardakani MR. Gingival biotype: a review. Gen Dent 2013;61:14-17.

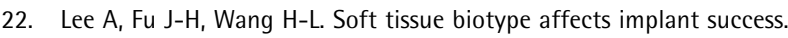
Implant Dent 2011;20:e38-e47. 